\title{
Acanthopanax senticosus Harms extract causes G0/G1 cell cycle arrest and autophagy via inhibition of Rubicon in human liver cancer cells
}

\author{
YUTAKA KAWANO $^{1}$, MAKI TANAKA ${ }^{2}$, MASAKI FUJISHIMA $^{3}$, ERI OKUMURA ${ }^{3}$, HIDEO TAKEKOSHI ${ }^{3}$, \\ KOHICHI TAKADA ${ }^{4}$, OSAMU UEHARA ${ }^{5}$, YOSHIHIRO ABIKO ${ }^{6}$ and HIDEKATSU TAKEDA ${ }^{7}$ \\ ${ }^{1}$ Department of Gastroenterology; ${ }^{2}$ Department of Clinical Laboratory Science, Health Sciences University of \\ Hokkaido Hospital, Sapporo, Hokkaido 002-8072; ${ }^{3}$ Production and Development Department, Sun Chlorella Co., Ltd., \\ Kyoto 600-8177; ${ }^{4}$ Department of Medical Oncology, Sapporo Medical University School of Medicine, Sapporo, \\ Hokkaido 060-8543; ${ }^{5}$ Division of Disease Control and Molecular Epidemiology, \\ Department of Oral Growth and Development; ${ }^{6}$ Division of Oral Medicine and Pathology, \\ Department of Human Biology and Pathophysiology, School of Dentistry, Health Sciences University of Hokkaido, \\ Tobetsu, Hokkaido 061-0293; ${ }^{7}$ Department of Physical Therapy, \\ Sapporo Medical University School of Medicine, Sapporo, Hokkaido 060-8543, Japan
}

Received October 9, 2020; Accepted January 8, 2021

DOI: $10.3892 /$ or.2021.7948

\begin{abstract}
Acanthopanax senticosus (Rupr. et Maxim) Harms (ASH), also known as Siberian ginseng or eleuthero, is a hardy shrub native to China, Korea, Russia and the northern region of Japan. ASH is used for the treatment of several diseases such as heart disease, hypertension, rheumatoid arthritis, allergies, chronic bronchitis, diabetes and cancer. In the present study, the inhibitory effect of the root extract of ASH (ASHE) on HuH-7 and HepG2 liver cancer cells was examined. ASHE suppressed liver cancer cell proliferation by inducing cell cycle arrest at the G0/G1 phase, as well as apoptosis, as indicated by the increased number of Annexin V and 7-AAD-positive cells. Furthermore, the expression of LC3-II, an autophagy marker, in these cells also increased post treatment with ASHE. LC3-II induction was further enhanced by co-treatment with chloroquine. Fluorescence and transmission electron micrographs of ASHE-treated liver cancer cells showed the presence of an increased number of autophagic vesicles. A decreased protein expression level of run domain Beclin-1-interacting and cysteine-rich domain-containing, an autophagy inhibitor, with no change in $R U B C N$ mRNA expression was observed, indicating activation of the autophagosome-lysosome fusion
\end{abstract}

Correspondence to: Dr Yutaka Kawano, Department of Gastroenterology, Health Sciences University of Hokkaido Hospital, 2-5 Ainosato, Kita-ku, Sapporo, Hokkaido 002-8072, Japan

E-mail: ykawano@hoku-iryo-u.ac.jp

Key words: Acanthopanax senticosus Harms, liver cancer, autophagy, run domain Beclin-1-interacting and cysteine-rich domain-containing step of autophagy. In conclusion, ASHE exerts cytostatic activity on liver cancer cells via both apoptosis and autophagy, and may serve as a potential therapeutic agent for management of liver cancer and autophagy-related diseases.

\section{Introduction}

Liver cancer is the fifth most common type of cancer, and the third most common cause of cancer-related death worldwide (1). Liver cancer usually occurs in patients with chronic hepatitis and cirrhosis, which limits the feasibility of curative therapies such as surgical resection and locoregional ablation therapy. Systemic chemotherapy, such as sorafenib and Lenvatinib, is used to treat patients with advanced liver cancer, which is associated with vascular invasion and metastasis. Recent advances in diagnostic imaging and supportive care for liver cancer have increased the duration of treatment periods and the quality of life of patients. However, the long-term survival in liver cancer remains unsatisfactory, with a median survival time of 12.3 months with sorafenib and 13.6 months with Lenvatinib treatment (2). Therefore, novel treatment strategies for liver cancer are required to achieve higher rates of patient survival.

Acanthopanax senticosus (Rupr. et Maxim) Harms (ASH), also known as Siberian ginseng or eleuthero, is a small hardy shrub native to China, Korea, Russia and the northern region of Japan (3). ASH is a well-known traditional Chinese medicinal herb, that possesses various pharmacological properties such as anti-fatigue, antioxidant, anti-protective and antibacterial activities (4-7). ASH is also known to exhibit therapeutic effects in several diseases, such as heart disease, hypertension, allergies (8), chronic bronchitis, diabetes (9), gastric ulcers (10), rheumatoid arthritis (11) and neurodegenerative diseases (12). Previous studies have also shown that 
ASH exhibits a cytotoxic effect on several cancer cell types. The stem bark of ASH inhibits tumor growth in stomach cancer (13), breast cancer (14) and leukemia (15), as well as the growth of sarcoma cells (16). However, the effect of ASH on liver cancer cells remains unknown. In the present study, the effects of ASH root extract on liver cancer cell lines was examined.

\section{Materials and methods}

Preparation of ASH extract. The ASH root extract (ASHE) used in the present study was prepared as described previously (17). Briefly, the roots of ASH were collected from the native area of Heilongjiang, China. The collected ASH roots (fresh weight $10 \mathrm{~kg}$ ) were cut and immersed in water for $3 \mathrm{~h}$ at $80^{\circ} \mathrm{C}$ to obtain extracts. The extract was then evaporated in vacuo, yielding \%50 g powder using a spray-drying method (10). ASHE (lot no. 8142) used in this experiment was prepared and supplied by Sun Chlorella Corp., and dissolved in distilled water to a concentration of $100 \mathrm{mg} / \mathrm{ml}$ for use in subsequent experiments.

Chemicals reagents. Chloroquine (CQ), bafilomycin A1 and 3-methyladenine (3-MA) were purchased from Sigma-Aldrich; Merck KGaA. The working concentrations of CQ were $0.5 \mu \mathrm{M}$ (HuH-7) or $2 \mu \mathrm{M}$ (HepG2). The working concentrations of bafilomycin A1 were $50 \mathrm{nM}$ (HuH-7) or $125 \mathrm{nM}$ (HepG2). The working concentrations of 3-MA were $0.1 \mathrm{mM}$ (HuH-7) or $0.3 \mathrm{mM}$ (HepG2). Treatment duration with CQ and 3-MA was $72 \mathrm{~h}$. Treatment duration of bafilomycin A1 was $2 \mathrm{~h}$.

Cell lines and culture conditions. The human liver cancer cell lines, HuH-7 (JCRB0403) and HepG2 (JCRB1054), were obtained from the Japanese Collection of Research Bioresources (JCRB), and cultured in DMEM supplemented with $10 \%$ FBS, $10 \mathrm{mM}$ L-glutamine, $100 \mathrm{U} / \mathrm{ml}$ penicillin and $100 \mu \mathrm{g} / \mathrm{ml}$ streptomycin (all from Sigma-Aldrich; Merck $\mathrm{KGaA}$ ) at $37^{\circ} \mathrm{C}$ in a humidified incubator with $5 \% \mathrm{CO}_{2}$.

Cell viability assay. HuH-7 and HepG2 cells were treated for 24,48 or $72 \mathrm{~h}$ with $62,125,250,500$ or $1,000 \mu \mathrm{g} / \mathrm{ml}$ ASHE in 96-well plates (Thermo Fisher Scientific, Inc.). Subsequently, cell viability was determined using the Premix WST-1 Cell Proliferation assay kit (Takara Bio Inc.) according to the manufacturer's protocol. Absorbance at $440 \mathrm{~nm}$ was measured using a microplate reader (Thermo Scientific Multiskan FC; Thermo Fisher Scientific, Inc.).

Colony formation assay. HuH-7 $\left(1 \times 10^{5}\right)$ and HepG2 $\left(5 \times 10^{4}\right)$ cells were seeded in 6-well plates (Thermo Fisher Scientific, Inc.), and treated with the indicated concentrations of ASHE for 5 days. After treatment, the colonies were fixed in $4 \%$ paraformaldehyde for $15 \mathrm{~min}$ at $4^{\circ} \mathrm{C}$, stained with $0.25 \%$ crystal violet for $15 \mathrm{~min}$ at room temperature, observed using a light microscope (magnification, $\mathrm{x} 400$ ) and imaged. A colony was defined to consist of $\geq 50$ cells.

Cell cycle assay. HuH-7 and HepG2 cells were allowed to adhere to 6-well plates for $24 \mathrm{~h}$ prior to treatment with ASHE. After incubation, cells were fixed with cold $70 \%$ ethanol for $2 \mathrm{~h}$, followed by staining with FxCycle propidium iodide (PI)/RNase
Staining Solution (Thermo Fisher Scientific, Inc.) according to the manufacturer's protocol. Stained cells were then analyzed using a BD FACSCanto II flow cytometer (BD Biosciences) with FACSDiva version 8.0.1 (BD Biosciences). Cell cycle analysis was performed using FlowJo version (FlowJo LLC).

Apoptosis assay. HuH-7 and HepG2 cells were allowed to adhere to 6-well plates, and were treated with ASHE for $72 \mathrm{~h}$. Treated cells were then harvested and washed, followed by staining with a phycoerythrin-conjugated Annexin V antibody (1:20) and 7-AAD (1:20) for $15 \mathrm{~min}$ at room temperature in the dark (BD Pharmingen). Apoptotic cells were analyzed using a BD FACSCanto II flow cytometer and the FACSDiva software. The percentage of apoptotic cells was calculated by dividing the percentage of either Annexin V-positive or 7-AAD-positive cells by the total number of cells.

Western blotting. Western blotting was performed as previously described (18). Briefly, the separated proteins were transferred to PVDF membranes and blotted with specific primary antibodies overnight at $4^{\circ} \mathrm{C}$. The primary antibodies used were AMPK $\alpha$ (1:1,000; Cell Signaling Technology, Inc.; cat. no. 2532), phospho-AMPK $\alpha$ (Thr172) (1:1,000; Cell Signaling Technology, Inc.; cat. no. 2535), LC3B (1:1,000; Cell Signaling Technology, Inc.; cat. no. 3868), Run domain Beclin-1-interacting and cysteine-rich domain-containing (Rubicon; 1:1,000; Cell Signaling Technology, Inc.; cat. no. 8465), c-Jun (1:1,000; Cell Signaling Technology, Inc.; cat. no. 9165), phospho-c-Jun (Ser63) (1:1,000; Cell Signaling Technology, Inc.; cat. no. 2361), SAPK/JNK (1:1,000; Cell Signaling Technology, Inc.; cat.no.9252), phospho-SAPK/JNK (Thr183/Tyr185) (1:1,000; Cell Signaling Technology, Inc.; cat. no. 9251) or actin (1:3,000; Santa Cruz Biotechnology, Inc.; cat. no. sc1615). After incubation for $1 \mathrm{~h}$ at room temperature with the secondary antibody, a horseradish peroxidase-conjugated anti-rabbit IgG (1:2,000; Cell Signaling Technology, Inc.; cat. no. 7074S), signals were visualized using ECL Select Western Blotting Detection Reagent (GE Healthcare). Finally, the bands were imaged using either ChemiDoc XRS Plus (Bio-Rad Laboratories, Inc.) or WSE-6100H LuminoGraphI (ATTO).

Fluorescence microscopy. HuH-7 and HepG2 cells were plated at a density of $1.2 \times 10^{5}$ cells/well in 12-well plates and allowed to adhere overnight. After ASHE treatment for $72 \mathrm{~h}$, the cells were incubated with $75 \mathrm{nM}$ DAPGreen (Dojindo Molecular Technologies, Inc.) and NucBlue Live ReadyProbes Reagent (Thermo Fisher Scientific, Inc.) at $37^{\circ} \mathrm{C}$ for $30 \mathrm{~min}$. After washing with PBS, fluorescence imaging was performed using a Leica DMi8 fluorescence microscope (magnification, $x 400$ ) and LAS X version 3.3 (Leica Microsystems, Inc.).

Transmission electron microscopy. ASHE-treated and untreated $\mathrm{HuH}-7$ cells were washed with PBS and fixed in $2 \%$ glutaraldehyde (in 0.1 M PBS, $\mathrm{pH} 7.4$ ) for $10 \mathrm{~min}$ at room temperature, and subsequently post-fixed with $2 \%$ osmium tetra-oxide for $2 \mathrm{~h}$ in an ice bath. Next, the specimens were dehydrated in graded concentrations of ethanol $(30,50,70,90$ and $100 \%$ ) and embedded in epoxy resin. Ultrathin sections were prepared using an ultramicrotome. These sections were stained with uranyl acetate for $15 \mathrm{~min}$ at room temperature 

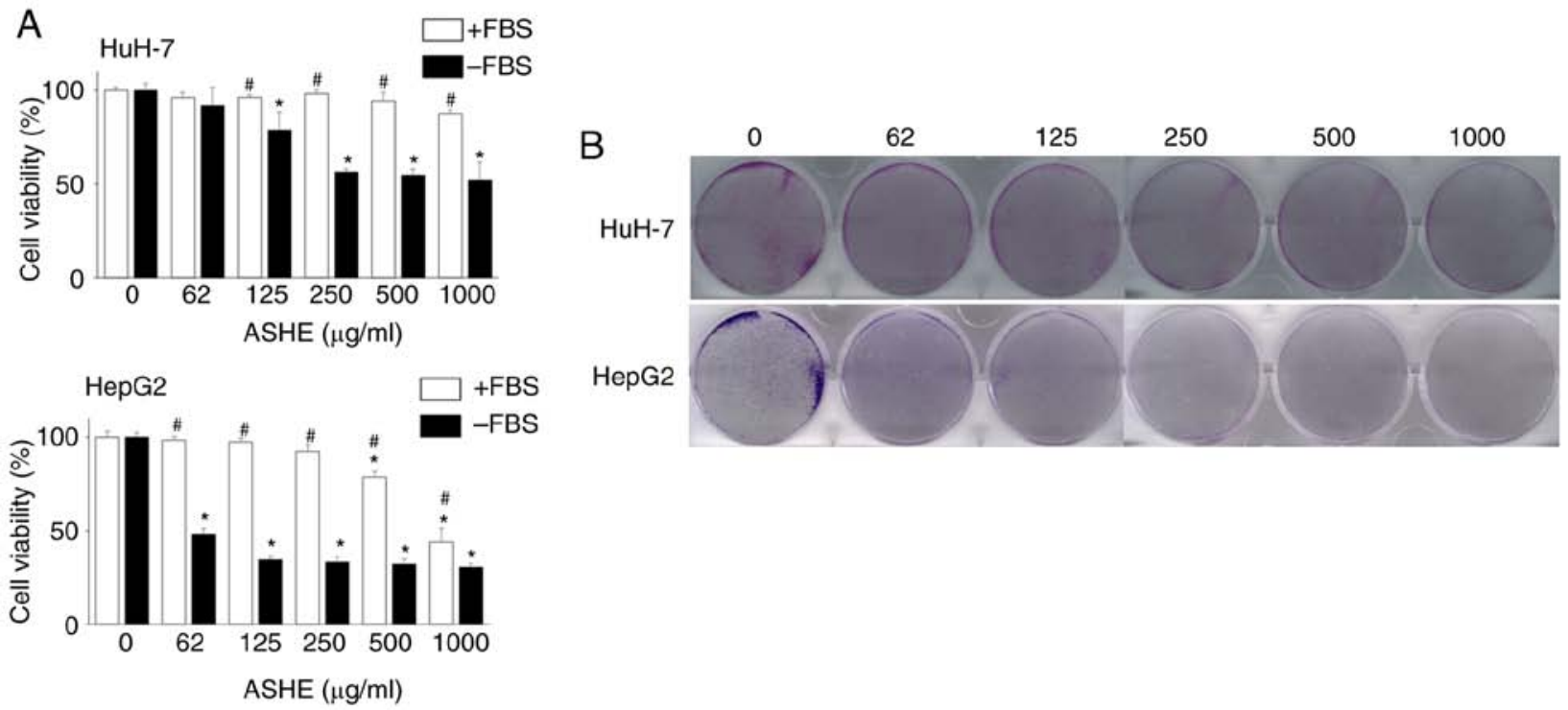

Figure 1. ASHE inhibits growth of liver cancer cells. (A) HuH-7 and HepG2 cells were treated with different concentrations of ASHE with or without FBS for $72 \mathrm{~h}$, and cell viability was measured. Data are presented as the mean \pm standard deviation of three independent experiments. "P<0.05 treated cells vs. untreated cells in the absence of FBS; ${ }^{\#} \mathrm{P}<0.05$ cells treated with ASHE in the presence of FBS compared with treated cells in the absence of FBS. (B) Representative images of crystal violet-stained colonies of ASHE-treated HuH-7 and HepG2 cells in the absence of FBS. ASHE, Acanthopanax senticosus Harms root extract.

and lead staining solution for $5 \mathrm{~min}$ at room temperature, and were observed using a HITACHI H-7600 transmission electron microscope (magnification, x5,000)(Hitachi, Ltd.) at a high voltage of $100 \mathrm{kV}$.

Reverse transcription-quantitative $(R T-q) P C R$. Total RNA from HuH-7 and HepG2 cells was isolated using TRIzol ${ }^{\circledR}$ reagent (Thermo Fisher Scientific, Inc.). cDNA was synthesized from $2 \mu \mathrm{g}$ total RNA using a SuperScript VILO cDNA Synthesis kit according to the manufacturer's protocol (Thermo Fisher Scientific, Inc.). The primer sequences for human Rubicon and $\beta$-actin genes were as follows: $R U B C N$ forward, 5'-GAT TACTGGCAGTTCGTGAAAGA-3' and reverse, 5'-CTGCTC TGGTCGTTCTCGTG-3'; ACTB ( $\beta$-actin) forward, 5'-GGC ATCCTCACCCTGAAGTA-3' and reverse, 5'-GAAGGTGTG GTGCCAGATTT-3'. qPCR was performed in triplicate using Power SYBR Green PCR mix (Thermo Fisher Scientific, Inc.). The thermocycling conditions were $3 \mathrm{~min}$ at $95^{\circ} \mathrm{C}$, followed by 40 cycles of $95^{\circ} \mathrm{C}$ for $3 \mathrm{sec}$, and $60^{\circ} \mathrm{C}$ for $20 \mathrm{sec}$. Changes in relative gene expression between cDNA samples were determined using the $2^{-\Delta \Delta \mathrm{Cq}}$ method (19).

Statistical analysis. All data are presented as the mean \pm standard deviation of three independent experiments. SPSS version 21 (IBM Corp.) was used to compare data. A two-tailed unpaired Student's t-test was used compare differences between two groups. Comparisons between control (non-treated) and ASHE-treated cells were performed using a one-way ANOVA followed by a post-hoc Tukey's test. $\mathrm{P}<0.05$ was considered to indicate a statistically significant difference.

\section{Results}

ASHE inhibits the proliferation of $\mathrm{HuH}-7$ and Hep $\mathrm{G} 2$ cells. HuH-7 and HepG2 cells were treated with different concentrations of ASHE $(62-1,000 \mu \mathrm{g} / \mathrm{ml})$ for $72 \mathrm{~h}$ to investigate the effects of ASHE on cell viability. ASHE had minimal effects on cell viability in these cell lines in the presence of FBS. However, in the absence of FBS, cell viability was significantly reduced in a dose-dependent manner (Fig. 1A). Colony formation assay also revealed the inhibitory effect of ASHE on the colony forming capacity of HuH-7 and HepG2 cells (Fig. 1B).

ASHE induces cell cycle arrest at the G0/G1 phase and inhibits cell viability. Flow cytometry of PI stained cells showed accumulation of cells in the G0/G1 phase, whereas the proportion of cells in the $\mathrm{S}$ phase decreased in both HuH-7 and HepG2 cells (Fig. 2A and B). Apoptosis analysis was used to examine whether cell cycle arrest at the G0/G1 phase could inhibit cell viability. Because the fluorescence intensity of both Annexin V-negative and 7-AAD-negative cells was increased in the cells treated with ASHE compared with the untreated cells, ASHE was determined to affect the fluorescence intensity (Fig. 2C). The number of both Annexin V-positive and 7-AAD-positive cells increased after treatment with ASHE (Fig. 2D), suggesting that apoptotic cell death occurred upon ASHE treatment.

ASHE promotes autophagic cell death in $\mathrm{HuH}-7$ and HepG2 cells. Previous studies on mice models showed that the fruit of the ASH tree modulates the autophagy regulator, AMPK (20), and that autophagy may trigger cell death in certain types of cells (21-23). Therefore, the effect of ASHE on AMPK activity and autophagy was assessed. No significant increase in the phosphorylation of AMPK was observed in ASHE-treated HuH-7 and HepG2 cells (Fig. 3A). Furthermore, LC3-II protein levels, a widely used marker for autophagic activity (24), were elevated in ASHE-treated HuH-7 and HepG2 cells compared with the untreated cells following treatment for 48 and $72 \mathrm{~h}$ (Fig. 3B and C). Thereafter, an LC3 turnover assay was performed to determine whether the increase in LC3-II protein levels was due to autophagy induction or inhibition (25). When 
A
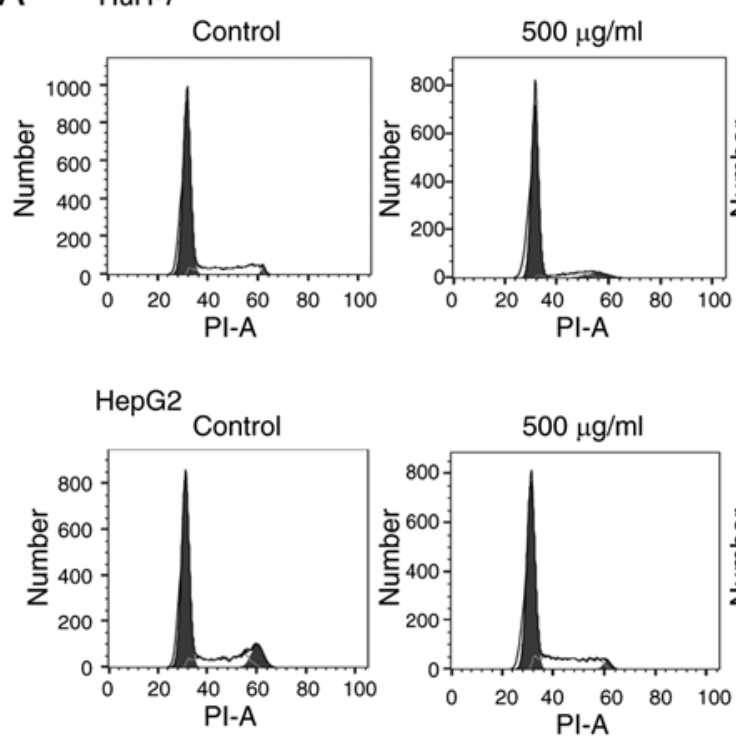

C
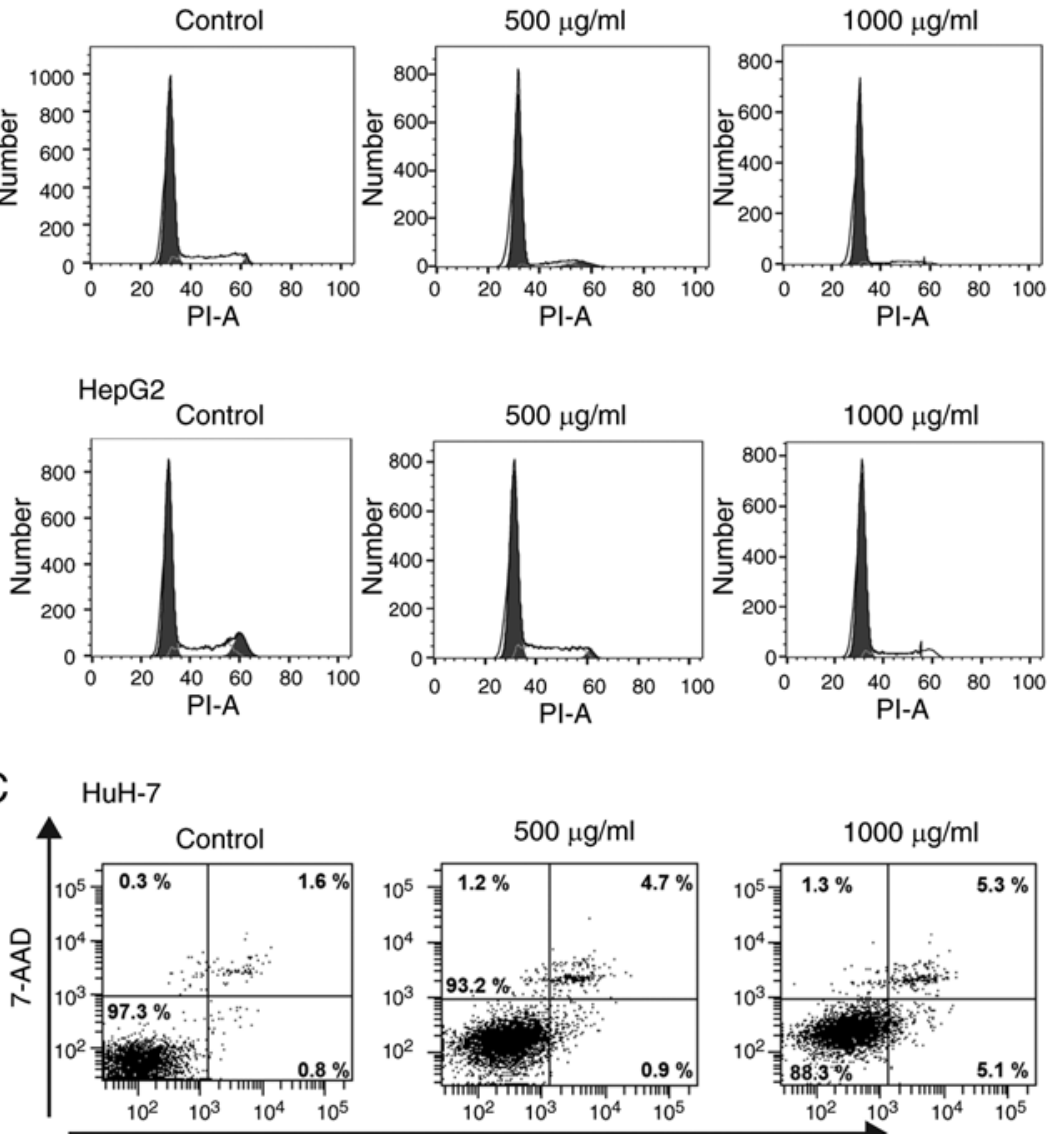

B
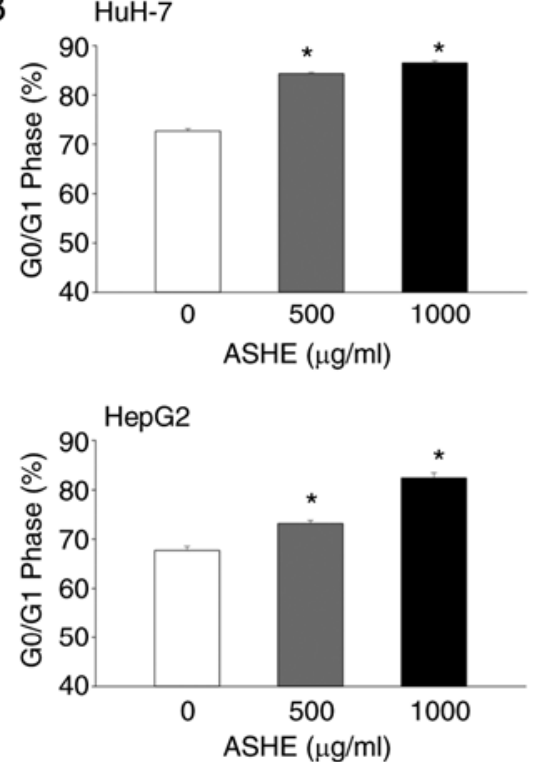

D
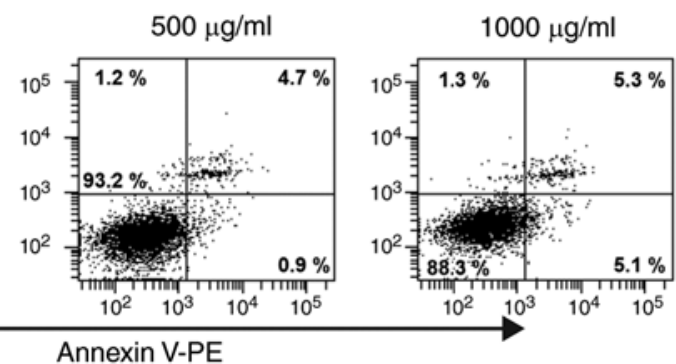

HepG2

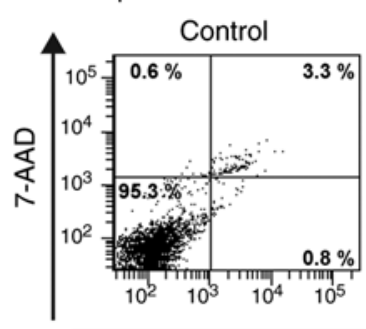

Annexin V-PE
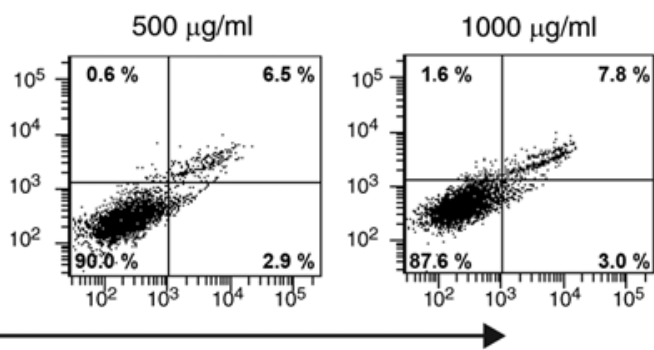

Annexin V-PE
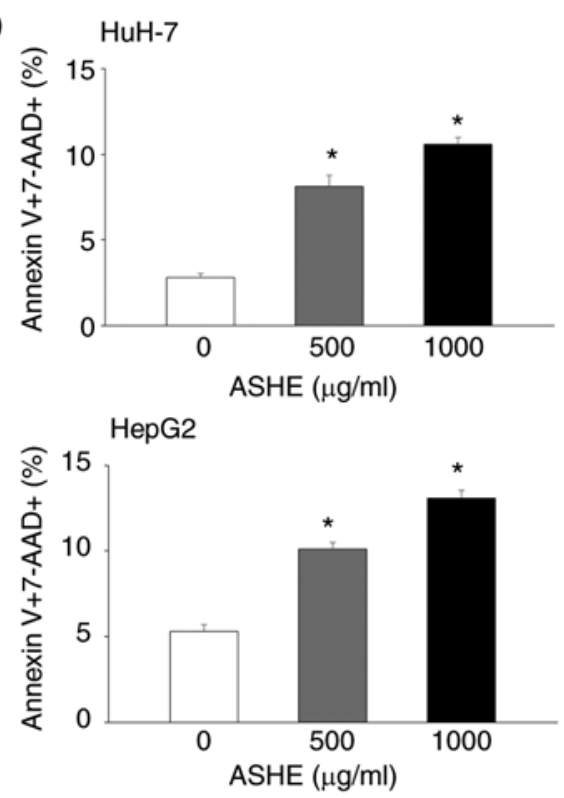

Figure 2. ASHE causes G0/G1 cell cycle arrest and induces apoptosis. (A) Representative flow cytometry histograms of cell cycle distribution. HuH-7 and HepG2 cells were treated with ASHE in the absence of FBS for $72 \mathrm{~h}$ and stained with PI. The gray area between 20 and 40 units of PI-A indicates the G0/G1 phase. (B) Percentage of HuH-7 and HepG2 cells in the G0/G1 phase with or without ASHE treatment (500 and 1,000 $\mu \mathrm{g} / \mathrm{ml}$. (C) Representative dot plot of cells stained with Annexin V-PE and 7-AAD. HuH-7 and HepG2 cells were treated with ASHE in the absence of FBS for $72 \mathrm{~h}$, followed by the assessment of apoptosis using flow cytometry. Values indicate the cell percentage in each quartile of the plots. (D) Percentage of either Annexin V-positive or 7-AAD-positive cells in HuH-7 and HepG2 cells. Data are presented as the mean \pm standard deviation of three independent experiments. "P<0.05 vs. untreated cells ASHE, Acanthopanax senticosus Harms root extract; 7-AAD, 7-actino; PE, phycoerythrin; PI, propidium iodide.

ASHE-treated HuH-7 and HepG2 cells were co-treated with $\mathrm{CQ}$, an inhibitor of degradation in autolysosomal compartments (26), LC3-II levels were further increased compared with ASHE treatment alone (Fig. 3D). In contrast, in the presence of bafilomycin A1, an autophagy inhibitor that blocks the fusion of autophagosomes and lysosomes (26), LC3-II levels remained unchanged irrespective of ASHE treatment (Fig. 3E). Thus, the LC3 turnover assay results suggested that ASHE enhanced autophagy by promoting autophagosome-lysosome fusion process, and not the degradative activity.

Next, DAPGreen was used to visualize the autophagic vacuoles in the ASHE-treated cells under a fluorescence microscope. As shown in Fig. 4A, the number of fluorescence-stained autophagic vacuoles increased in $\mathrm{HuH}-7$ and HepG2 cells in an ASHE dose-dependent manner. The ultrastructure of ASHE-treated HuH-7 cells was assessed using transmission electron microscopy to further confirm whether the vacuoles were the result of autophagy (Fig. 4B). Both the number and the percentage area of autophagic structures was increased in ASHE-treated cells compared with those in the untreated cells in a dose-dependent manner (Fig. S1A, B). Furthermore, to examine the effect of autophagy on cell viability, the cells were treated with 3-MA, which inhibits autophagy at an early stage, instead of CQ and bafilomycin A1 . 
A

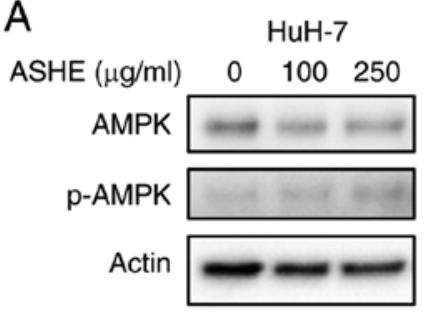

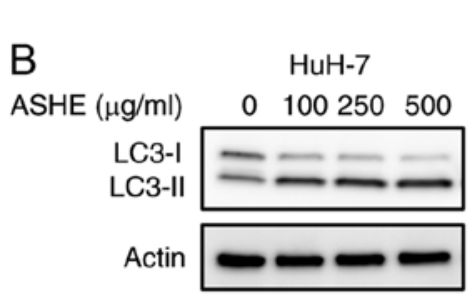

C
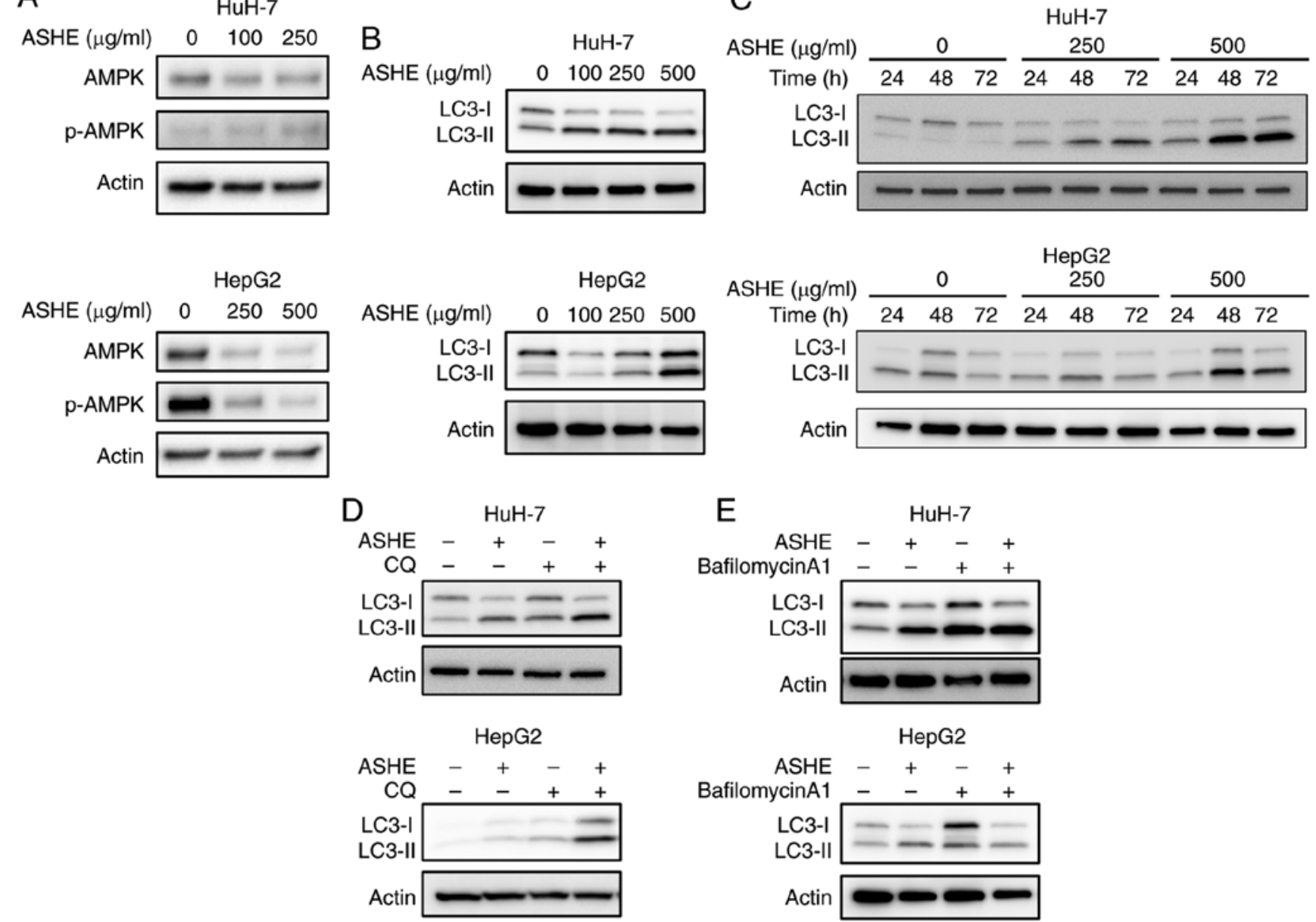

Figure 3. LC3-II expression is increased via promotion of autophagy flux in ASHE-treated liver cancer cells. Effect of ASHE on (A) AMPK, phosphorylated AMPK, and (B) LC3-I and LC3-II in HuH-7 and HepG2 cells. HuH-7 and HepG2 cells were treated with ASHE (HuH7: 0, 100 or 250 $\mu$ g/ml; HepG2: 0, 250 and $500 \mu \mathrm{g} / \mathrm{ml}$ ) for $72 \mathrm{~h}$. (C) Effect of ASHE treatment for different time periods on LC3-I and LC3-II protein expression. HuH-7 and HepG2 cells were treated with ASHE in the absence of FBS for the indicated time periods and concentrations. ASHE-treated HuH-7 and HepG2 cells were co-treated with either (D) CQ $(0.5$ or $2 \mu \mathrm{M})$ for $72 \mathrm{~h}$, or (E) bafilomycin A1 (50 or $125 \mathrm{nM})$ for $2 \mathrm{~h}$. Protein expression was detected by western blotting. Actin was used as the loading control. ASHE, Acanthopanax senticosus Harms root extract; CQ, chloroquine.

Growth inhibition was partially attenuated in HuH-7 cells co-treated with 3-MA and ASHE compared with cells treated with ASHE alone (Fig. 4C). A similar result was also observed in HepG2 cells at low ASHE concentrations.

ASHE decreases Rubicon expression in $\mathrm{HuH}-7$ and HepG2 cells. As co-treatment with bafilomycin A1 did not enhance LC3-II expression in ASHE-treated cells (Fig. 3E), the protein expression of Rubicon was examined, which inhibits autophagosome and lysosome fusion by binding to the UVRAG complex. UVRAG serves as an autophagy-associated protein by binding to Beclin-1 and functions in the autophagy maturation process (27). The protein expression of Rubicon in ASHE-treated HepG2 and HuH-7 cells was lower than that in untreated cells (Fig. 5A). Regulation of Rubicon protein expression is mediated by the JNK signaling pathway in hepatocytes (28). However, western blotting results showed no decrease in the phosphorylation of either c-Jun or SAPK/JNK in both HuH-7 and HepG2 cells following treatment with ASHE (Fig. 5B). Notably, no significant change in Rubicon expression was observed in HuH-7 and HepG2 cells treated with ASHE in the presence of either CQ or bafilomycin A1 (Fig. S2). Moreover, no decrease in $R U B C N$ mRNA expression was observed in ASHE-treated cells compared with the untreated cells (Fig. S3).

\section{Discussion}

In the present study, it was demonstrated that ASHE exhibits cytostatic effects mediated by apoptosis and autophagy in liver cancer cells by inhibiting Rubicon protein expression. This effect was partially attenuated by co-treatment with the autophagy inhibitor, 3-MA, suggesting that the mechanism underlying the reduction in cell viability of liver cancer cells by ASHE may involve autophagy.

ASHE is a widely used component of Chinese traditional medicine prescribed for the treatment of several diseases, such as heart disease, hypertension, allergies (8), chronic bronchitis, diabetes (9), gastric ulcers (10), rheumatoid arthritis (11) and neurodegenerative disease (12). Previous studies have shown that ASHE triggers apoptosis in stomach (13) and breast cancer cells (14); however, this effect is not evident in leukemia (15) and sarcoma cells (16). Thus, ASHE exhibits diverse cytotoxic effects in cells of different cancer types. Moreover, a previous study showed that the polysaccharides extracted from ASH 
A

$\operatorname{ASHE}(\mu \mathrm{g} / \mathrm{ml})$

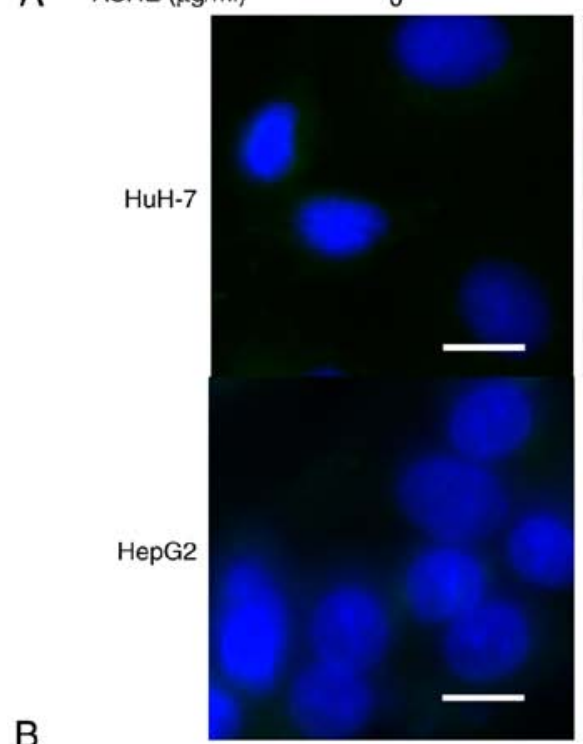

B

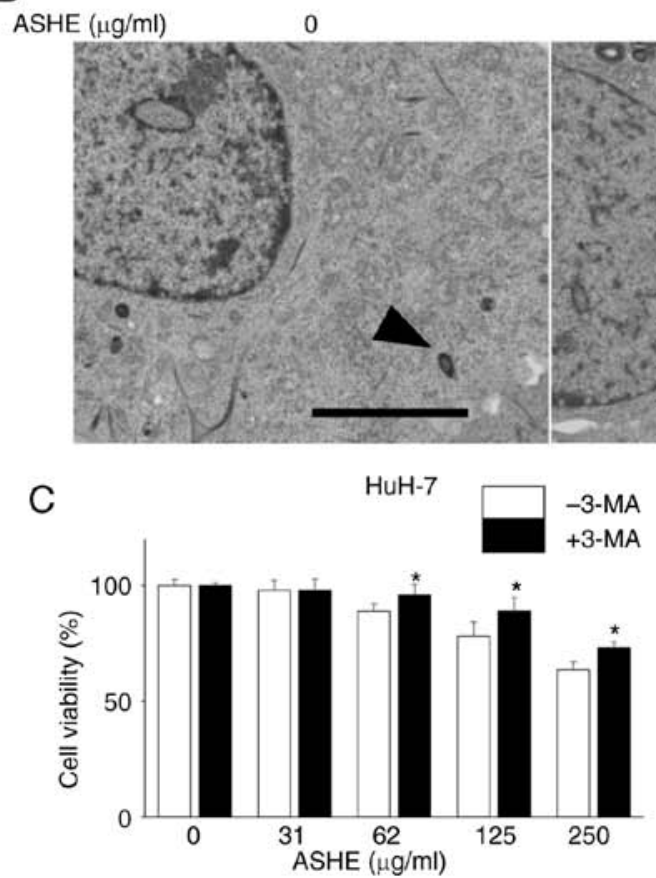

100

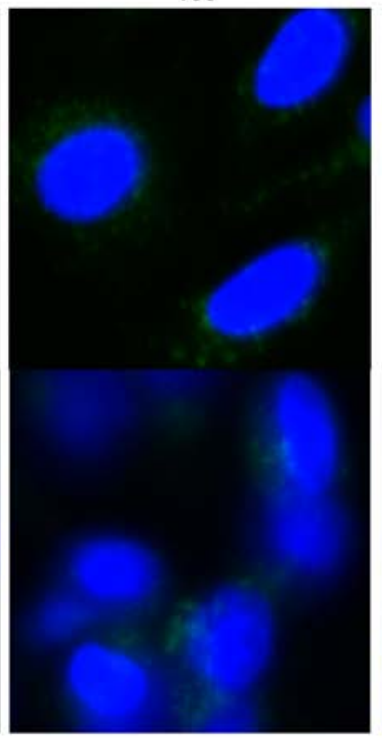

100
250

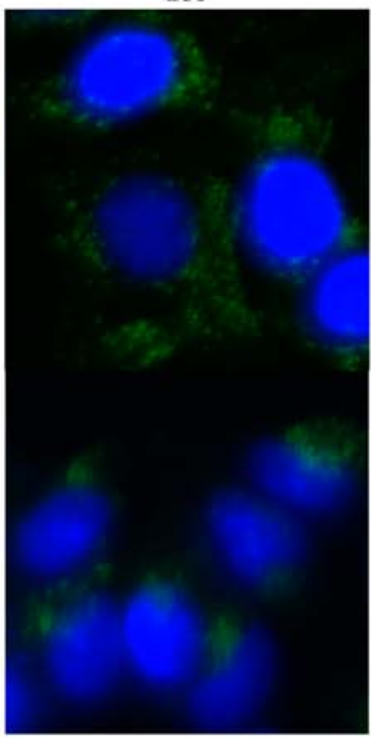

250
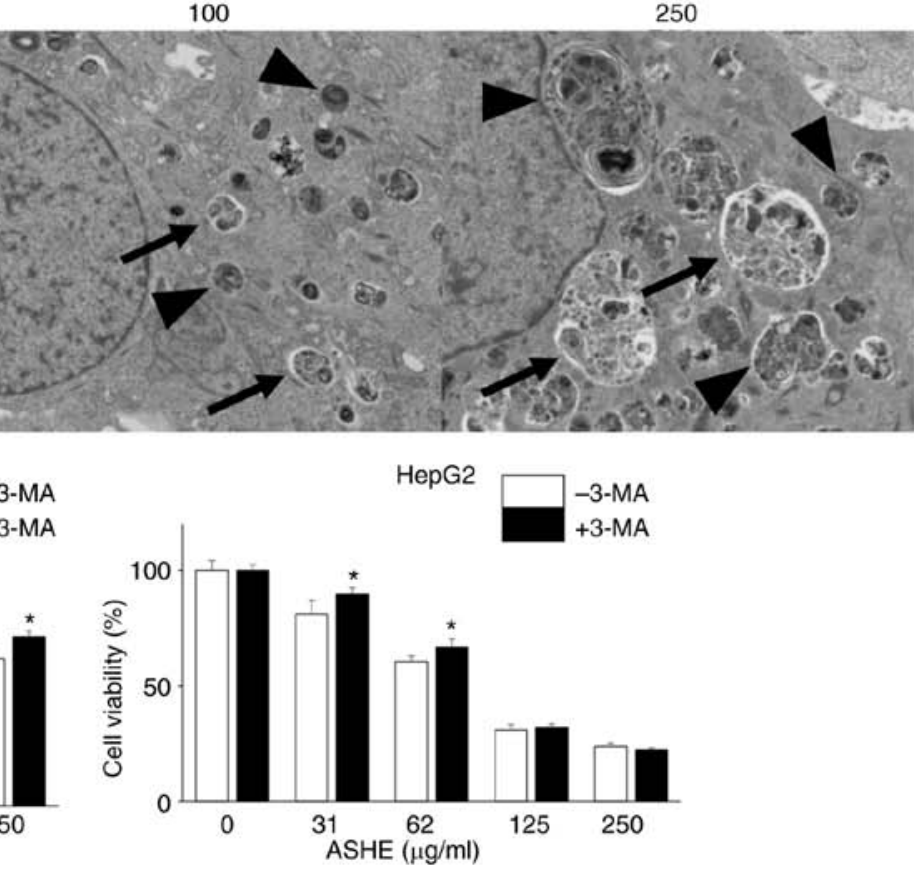

Figure 4. Autophagic vesicle quantity is increased in ASHE-treated liver cancer cells. (A) Fluorescence micrographs of HuH-7 and HepG2 cells treated with ASHE in the absence of FBS for $72 \mathrm{~h}$. Following treatment, cells were incubated with DAPGreen (50 nM) for $30 \mathrm{~min}$. Magnification, $\mathrm{x} 400$. Scale bar, $10 \mu \mathrm{m}$. (B) Representative transmission electron micrographs of HuH-7 cells treated with ASHE in the absence of FBS. Arrows indicate autophagosomes, and arrowheads indicate autolysosomes. Magnification, x5,000. Scale bar, $5 \mu \mathrm{m}$. (C) ASHE-treated HuH-7 and HepG2 cells were co-treated with 3-MA $(0.1$ or $0.3 \mathrm{mM})$ for $72 \mathrm{~h}$, followed by measurement of cell viability. Data are presented as the mean \pm standard deviation of three independent experiments. ${ }^{*} \mathrm{P}<0.05$ vs. ASHE-treated cells in the absence of 3-MA. ASHE, Acanthopanax senticosus Harms root extract; 3-MA, 3-methyladenine.

root caused pronounced apoptosis in HepG2 cells (29). As crude ASHE was used in the present study, the apoptotic effect of ASHE was not observed.

Autophagy is a catabolic process that delivers endogenous cytoplasmic content to the lysosome, followed by degradation and recycling of proteins and organelles. Dysregulation of autophagy is known to contribute towards protection of organisms against pathologies, such as infections, heart disease, neurodegeneration, aging and cancer (30). Autophagy functions as either an inducer or inhibitor of cell death in cancer cells. In the present study, ASHE-mediated autophagy promoted cell death in cooperation with apoptosis in liver cancer cells. As the cytotoxicity of ASHE was most evident in the absence of FBS, it is proposed that FBS is an inhibitor of ASHE-induced autophagy.

During autophagy induction, LC3 protein is synthesized and processed by Atg4 into LC3-I, followed by conversion to LC3-II, which is conjugated with phosphatidylethanolamine. Therefore, LC3 is commonly used for autophagy assays (24). The results of the present study showed that LC3-II protein expression levels were increased in ASHE-treated cells compared with the untreated cells. The difference in LC3-I levels between HuH-7 and HepG2 cells suggests different LC3-I to LC3-II conversion rates in the two cell types. 
A

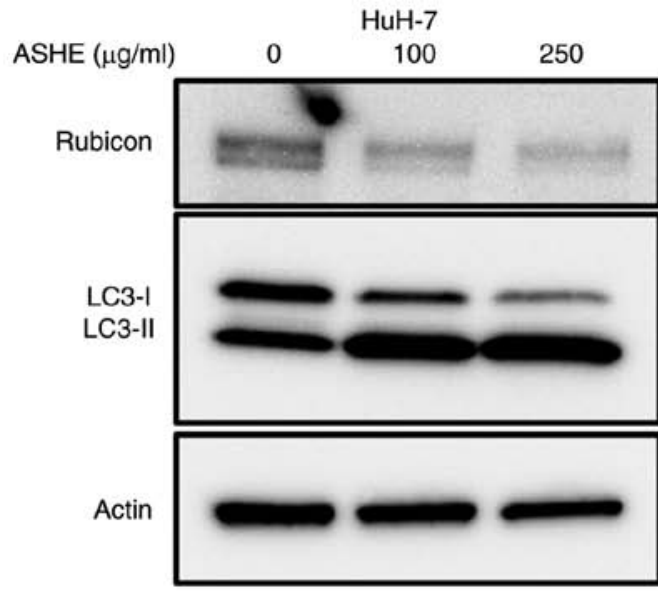

B

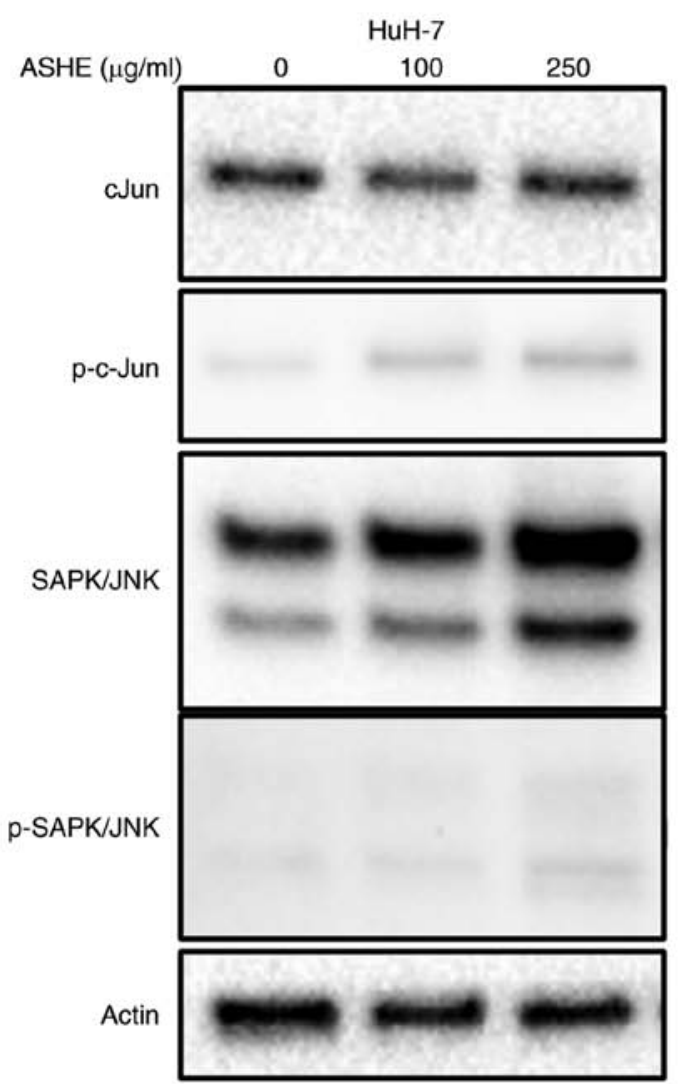

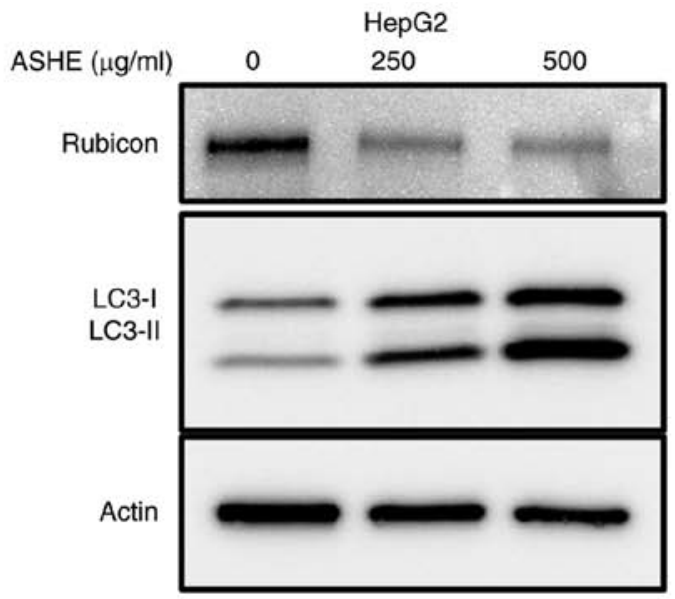

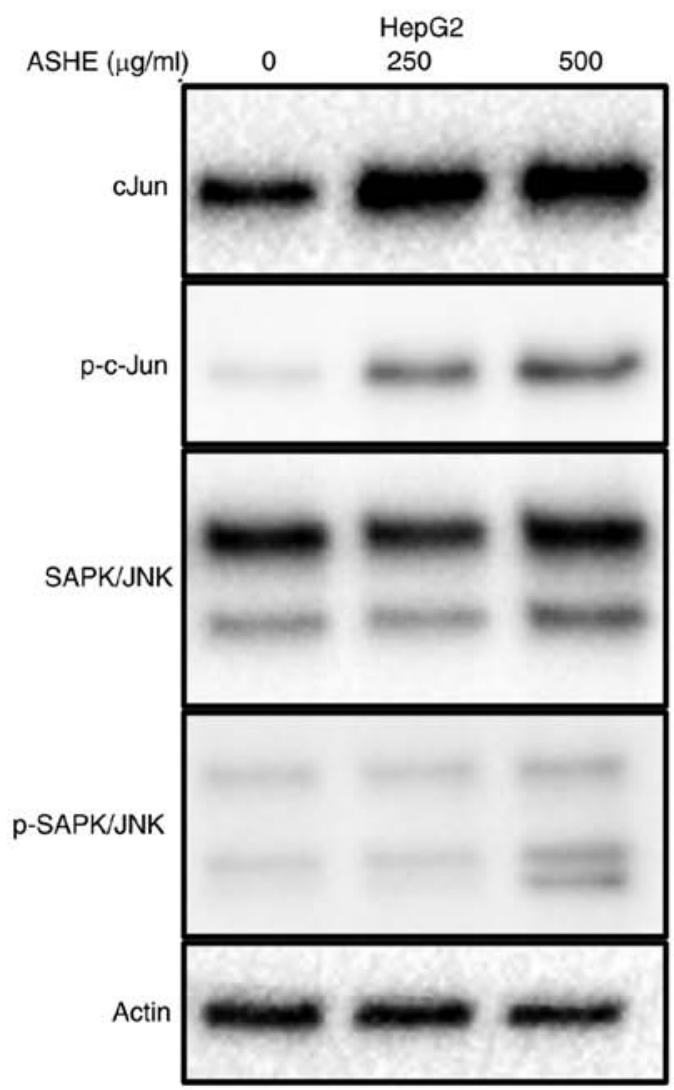

Figure 5. Decreased Rubicon protein expression in ASHE-treated liver cancer cells. Protein expression of (A) Rubicon and (B) Rubicon-related proteins. HuH-7 and HepG2 cells were treated with ASHE at the indicated concentrations in absence of FBS. Protein expression was detected by western blotting. Actin was used as the loading control. ASHE, Acanthopanax senticosus Harms root extract; p-, phospho-; Rubicon, run domain Beclin-1-interacting and cysteine-rich domain-containing.

Autophagy serves dual roles in cancer development depending on the cancer type, stage or genetic context $(21,30)$. Rubicon protein inhibits autophagy by suppressing the fusion of autophagosomes and lysosomes (27). This protein is upregulated by the JNK pathway in palmitate-treated hepatocytes in fatty liver (28). In the present study, the total amount of both c-Jun or SAPK/JNK proteins in HuH-7 and HepG2 cells increased after ASHE treatment, suggesting the presence of a factor that promotes the transcription of these proteins in ASHE. Nevertheless, neither the JNK pathway nor the transcription of $R U B C N$ was inhibited in ASHE-treated liver cancer cells. Notably, the expression of Rubicon protein in ASHE-treated HepG2 and HuH-7 cells was decreased. Thus, inhibiting
Rubicon protein may be a promising approach for the treatment of fatty liver (28), and therefore, validation of this effect using other liver cancer cell lines is required. Additionally, as ASHE induces autophagy as well as inhibiting Rubicon expression in cell lines other than liver cancer cell lines, autophagy-related diseases of other organs may also be treated using ASHE.

In the present study, the increase in autophagic flux after ASHE treatment in HuH-7 and HepG2 cells was independent of the inhibition of Rubicon protein expression. Thus, unlike metformin, which suppresses the mammalian target of the rapamycin (mTOR) pathway (31), ASHE showed no positive regulatory effect on AMPK activation. ASHE has four major bioactive components, isofraxidin, eleutheroside B, 
eleutheroside $\mathrm{E}$ and chlorogenic acid (3). Isofraxidin, eleutheroside $\mathrm{B}$, and chlorogenic acid offers protection against damage from radiation and oxidation. Eleutheroside $\mathrm{E}$ is reported to exhibit anti-inflammatory effects. As these components are not known to induce autophagy, to the best of our knowledge, further studies are required to determine the mechanism underlying ASHE-mediated autophagy promotion.

In conclusion, the mechanism of ASHE action in liver cancer cells was shown to involve autophagy. Decreased expression of Rubicon protein upon ASHE treatment promotes the fusion of autophagosomes and lysosomes, and leads to autophagy. As crude ASHE affected liver cancer cell autophagy in the absence of FBS, treatment with ASHE may not be practical in clinical settings, where there are sufficient nutrients. Isolating the ASHE components that inhibit Rubicon expression and promote autophagic flux, even in the presence of FBS, may facilitate its application for the treatment of diseases associated with autophagy dysregulation.

\section{Acknowledgements}

We would like to thank Miss Rieko Naganuma (Hanaichi UltraStructure Research Institute Co. Ltd.), Miss Yukie Nakamura (Health Sciences University of Hokkaido), and Miss Mayumi Shitamichi (Health Sciences University of Hokkaido) for their assistance with this research project.

\section{Funding}

This study was funded by Sun Chlorella Co., Ltd.

\section{Availability of data and materials}

The datasets used and/or analyzed during the present study are available from the corresponding author upon reasonable request.

\section{Authors' contributions}

YK, MT and OU performed the experiments. MF, EO and HTakek provided and prepared the ASH extracts. YK, KT and HTaked participated in the design of the study. YK, OU and YA participated in the writing of the manuscript and data analysis. YK and MT confirm the authenticity of all the raw data. All authors read and approved the final manuscript.

\section{Ethics approval and consent to participate}

Not applicable.

\section{Patient consent for publication}

Not applicable.

\section{Competing interests}

MF, EO and HT are employees of Sun Chlorella Co., Ltd. They all had no role in the interpretation, drafting or decision to publish the manuscript.

\section{References}

1. Marrero JA,KulikLM,Sirlin CB,Zhu AX,Finn RS, Abecassis MM, Roberts LR and Heimbach JK: Diagnosis, staging, and management of hepatocellularcarcinoma: 2018 practice guidancebythe American association for the study of liver diseases. Hepatology 68: 723-750, 2018.

2. Kudo M, Finn RS, Qin S, Han KH, Ikeda K, Pscaglia F, Bari A, Park JW, Han G, Jassem J, et al: Lenvatinib versus sorafenib in first-line treatment of patients with unresectable hepatocellular carcinoma: A randomised phase 3 non-inferiority trial. Lancet 391: 1163-1173, 2018.

3. Davydov M and Krikorian AD: Eleutherococcus senticosus (Rupr. \& Maxim.) Maxim. (Araliaceae) as an adaptogen: A closer look. J Ethnopharmacol 72: 345-393, 2000.

4. Nishibe S, Kinoshita H, Takeda H and Okano G: Phenolic compounds from stem bark of Acanthopanax senticosus and their pharmacological effect in chronic swimming stressed rats. Chem Pharm Bull (Tokyo) 38: 1763-1765, 1990.

5. Lee S, Son D, Ryu J, Lee YS, Jung SH, Kang J, Lee SY, Kim HS and Shin KH: Anti-oxidant activities of Acanthopanax senticosus stems and their lignan components. Arch Pharm Res 27: 106-110, 2004.

6. Jang MH, Shin MC, Kim YJ, Kim CJ and Chung JH: Protective effect of Acanthopanax senticosus against ethanol-induced apoptosis of human neuroblastoma cell line SK-N-MC. Am J Chin Med 31: 379-388, 2003.

7. Lee S, Shin DS, Oh KB and Shin KH: Antibacterial compounds from the leaves of Acanthopanax senticosus. Arch Pharm Res 26: 40-42, 2003.

8. Yi JM, Hong SH, Kim JH, Kim HK, Song HJ and Kim HM: Effect of Acanthopanax senticosus stem on mast cell-dependent anaphylaxis. J Ethnopharmacol 79: 347-352, 2002.

9. Liu KY, Wu YC, Liu IM, Yu WC and Cheng JT: Release of acetylcholine by syringin, an active principle of Eleutherococcus senticosus, to raise insulin secretion in Wistar rats. Neurosci Lett 434: 195-199, 2008.

10. Fujikawa T, Yamaguchi A, Morita I, Takeda $\mathrm{H}$ and Nishibe $\mathrm{S}$ : Protective effects of Acanthopanax senticosus Harms from Hokkaido and its components on gastric ulcer in restrained cold water stressed rats. Biol Pharm Bull 19: 1227-1230, 1996.

11. Takahashi Y, Tanaka M, Murai R, Kuribayashi K, Kobayashi D, Yanagihara $\mathrm{N}$ and Watanabe N: Prophylactic and therapeutic effects of Acanthopanax senticosus Harms extract on murine collagen-induced arthritis. Phytother Res 28: 1513-1519, 2014.

12. Liu SM, Li XZ, Zhang SN, Yang ZM, Wang KX, Lu F, Wang CZ and Yuan CS: Acanthopanax senticosus protects structure and function of mesencephalic mitochondria in a mouse model of Parkinson's disease. Chin J Integr Med 24: 835-843, 2018.

13. Hibasami H, Fujikawa T, Takeda H, Nihibe S, Satoh T, Fujisawa T and Nakashima K: Induction of apoptosis by Acanthopanax senticosus HARMS and its component, sesamin in human stomach cancer KATO III cells. Oncol Rep 7: 1213-1216, 2000.

14. Siao AC, Hou CW, Kao YH and Jeng KC: Effect of sesamin on apoptosis and cell cycle arrest in human breast cancer mcf-7 cells. Asian Pac J Cancer Prev 16: 3779-3783, 2015.

15. Wang QY, Zhong H, Chen FY, Zhang MY, Cai JY and Xhong JH: A preliminary study on epigenetic regulation of Acanthopanax senticosus in leukemia cell lines. Exp Hematol 44: 466-473, 2016.

16. Yamazaki T, Shimosaka S, Sasaki H, Matsumura T, Tukiyama T and Tokiwa T: (+)-Syringaresinol-di-O- $\beta$-D-glucoside, a phenolic compound from Acanthopanax senticosus Harms, suppresses proinflammatory mediators in SW982 human synovial sarcoma cells by inhibiting activating protein-1 and/or nuclear factor- $\kappa \mathrm{B}$ activities. Toxicol in Vitro 21: 1530-1537, 2007.

17. Miyazaki S, Oikawa H, Takekoshi H, Hoshizaki M, Ogata M and Fujikawa T: Anxiolytic effects of Acanthopanax senticosus HARMS occur via regulation of autonomic function and activate hippocampal BDNF-TrkB signaling. Molecules 24: 132, 2018.

18. Ishikawa K, Kawano Y, Arihara Y, Kubo T, Takada K, Murase K, Miyanishi K, Kobune M and Kato J: BH3 profiling discriminates the antiapoptotic status of 5-fluoro-uracil-resistant colon cancer cells. Oncol Rep 42: 2416-2425, 2019.

19. Kamihara Y, Takada K, Sato T, Kawano Y, Murase K, Arihara Y, Kikuchi S, Hayasaka N, Usami M, Iyama S, et al: The iron chelator deferasirox induces apoptosis by targeting oncogenic Pyk $2 / \beta$-catenin signaling in human multiple myeloma. Oncotarget 7: 64330-64341,2016. 
20. Saito T, Nishida M, Saito M, Tanabe A, Eitsuka T, Yuan SH, Ikekawa $\mathrm{N}$ and Nishida $\mathrm{H}$ : The fruit of Acanthopanax senticosus (Rupr. et Maxim.) Harms improves insulin resistance and hepatic lipid accumulation by modulation of liver adenosine monophosphate-activated protein kinase activity and lipogenic gene expression in high-fat diet-fed obese mice. Nutr Res 36: 1090-1097, 2016.

21. Debnath J, Baehrecke EH and Kroemer G: Does autophagy contribute to cell death? Autophagy 1: 66-74, 2005.

22. Espert L, Denizot M, Grimaldi M, Robert-Hebmann V, Gay B, Varbano M, Codogno P and Biard-Piechaczyk M: Autophagy is involved in T cell death after binding of HIV-1 envelope proteins to CXCR4. J Clin Invest 116: 2161-2172, 2006.

23. Shimizu S, Kanaseki T, Mizushima N, Mizuta T, Arakawa-Kobayashi S, Thompson CB and Tsujimoto Y: Role of $\mathrm{Bcl}-2$ family proteins in a non-apoptotic programmed cell death dependent on autophagy genes. Nat Cell Biol 6: 1221-1228, 2004.

24. Mizushima $\mathrm{N}$ and Yoshimori T: How to interpret LC3 immunoblotting. Autophagy 3: 542-545, 2007.

25. Mizushima N, Yoshimori T and Levine B: Methods in mammalian autophagy research. Cell 140: 313-326, 2010.

26. Iwashita H, Sakurai HT, Nagahora N, Ishiyama M, Shioji K, Sasamoto K, Okuma K, Shimizu S and Ueno Y: Small fluorescent molecules for monitoring autophagic flux. FEBS Lett 592: $559-567,2018$
27. Matsunaga K, Saitoh T, Tabata K, Omori H, Satoh T, Kurotori N, Maejima I, Shirahama-Noda K, Ichimura T, Isobe T, et al: Two Beclin 1-binding proteins, Atg14L and Rubicon, reciprocally regulate autophagy at different stages. Nat Cell Biol 11: 385-396, 2009.

28. Suzuki A, Kakisaka K, Suzuki Y, Wang T and Takikawa Y: C-Jun N-terminal kinase-mediated Rubicon expression enhances hepatocyte lipoapoptosis and promotes hepatocyte ballooning. World J Gastroenterol 22: 6509-6519, 2016.

29. Wang H, Sun B, Zhang Z, Chen J, Hao Q, Sun Y, Yang Y, Wang Z and Pei J: Effects of Acanthopanax senticosus polysaccharide on the proliferation, apoptosis and cell cycle in human HepG2 cells. Pharmazie 71: 201-204, 2016.

30. Levine B and Kroemer G: Autophagy in the pathogenesis of disease. Cell 132: 27-42, 2008

31. Wang Y, Xu W, Yan Z, Zhao W, Mi J, Li J and Yan H: Metformin induces autophagy and G0/G1 phase cell cycle arrest in myeloma by targeting the AMPK/mTORC1 and mTORC2 pathways. J Exp Clin Cancer Res 37: 63, 2018

(i) (3) This work is licensed under a Creative Commons Attribution-NonCommercial-NoDerivatives 4.0 International (CC BY-NC-ND 4.0) License. 